\title{
Research on the Course Construction of Internet Plus Food Chemistry under the Background of Applied Technology Transformation*
}

\author{
Chunyan Niu \\ College of Food Engineering \\ Jilin Agricultural Science and Technology University \\ Jilin, China 132101
}

\author{
Wenyi Yan \\ College of Food Engineering \\ Jilin Agricultural Science and Technology University \\ Jilin, China 132101
}

\author{
Xiaokun Jiang \\ College of Food Engineering \\ Jilin Agricultural Science and Technology University \\ Jilin, China 132101
}

\begin{abstract}
The Food Chemistry course is a very important discipline platform course for food majors under the background of applied technology transformation. This paper discusses the reform and exploration of the Internet plus Food Chemistry course from research objectives and research content.
\end{abstract}

Keywords-background of transformation; food chemistry; internet plus

\section{INTRODUCTION}

With the development of modern food direction, many institutions at home and abroad have set up related courses in food chemistry on the premise that relevant majors in food science are set up gradually to adapt to the needs of actual analytical and management. There are differences in research status at home and abroad in the field of food chemistry curriculum construction ${ }^{[1-3]}$. From the requirements of the talent training objective, taking the foreign IFT (Institute of Food Technologists ) as an example, the basic requirements it proposes are relatively simple compared with the requirements of Teaching Steering Committee in China, and the content covered is also relatively little. Compared with the research content and credit setting of the food chemistry courses already established in colleges and universities both at home and abroad, it can be seen that there are also large differences between colleges and universities. Influenced by culture, education, economy, and so on, there are also many differences in the teaching mode of Food Chemistry course at home and abroad. In order to achieve a better connection with

\footnotetext{
*Project source:

2017 Higher Education Scientific Research Project of Jilin Provincial Association of Higher Education (No. JGJX2017D233)

2017 College Students Technology Innovation Project of Jilin Agricultural Science and Technology University

About the author: Chunyan Niu (1981-), female, Ph.D., comes from Qian'an, Jilin, and is mainly engaged in the teaching and scientific research of food chemistry and other courses.
}

actual production and to improve teaching effect, this topic studies the construction and practice of the Food Chemistry course in the food major. The introduction of information resources in the field of education forms an open resource library and the establishment of teaching platform constitutes the basic model of the current "Internet + education". This can optimize teaching resources, improve teaching effectiveness, and can better serve the improvement of teaching quality. It is also a systematic project in the construction of food courses, and also of great significance in solving the emerging teaching problems ${ }^{[4-6]}$. Whether the courses are scientific and reasonable is directly related to the quality of personnel training. Therefore, it is of great significance to the construction and reform of modernization of vocational education of technical colleges and universities to study and explore Food Chemistry course.

\section{RESEARCH OBJECT}

In the light of the training objectives of applied technical students, we need to combine the requirements of future work and students' research results. This topic explores the reform and practice of Internet plus Food Chemistry course from two aspects including research objectives and the main research content, and establishes a featured food chemistry curriculum teaching system combining with the major with modern professional education. Only in this way can we improve the actual operation and control the balance ability of food items, and then enhance the effect of teaching reform and practice.

\section{SPECIFIC DESIGN LINK}

\section{A. Start from the Characteristics of Talent Training, and Optimize Teaching Content}

The features of talent training of this major are to cultivate the advanced applied persons who shall support our party's basic policy with all-round development of morality, 
intelligence, physique and aesthetics, who adapt to the demands of socialist development and face the needs of industry, market, economy and society, who shall master the basic theory, basic knowledge and basic skills of animal and plant quarantine with strong practical ability, who shall equip with the ability of epidemic prevention and quarantine of animal and plant disease, and safety and supervision of animal and plant products. On this basis, we have established a talent training mode of "one cooperation, one mainline and twocycle", namely, college-enterprise cooperation. We take the ability training as the main line and adopt the dual cycle talent training mode of "theory-practice-learning theory againpractice again...". In the past three years, the graduation rate of the graduates of this major is $100 \%$, and the rate of degree awarding is $94.8 \%$, and the rate of post graduate qualifications is above $30 \%$, and the employment rate of students is above 97\%.Graduates are able to perform laboratory tests, quality control, product $\mathrm{R} \& \mathrm{D}$, and administrative management on the forefront of production of large and medium-sized food companies, as well as the control and management of food safety production, food analysis and testing, food distribution and management in Food and Drug Administration, Bureau of Quality and Technical Supervision, Center for Disease Control and Prevention, Food Science Research Institute and other units.

Therefore, before the implementation of teaching, we should choose appropriate teaching materials based on the characteristics of the major, the student's knowledge structure and training objectives. In addition, we should optimize the teaching content properly, and select the basic theories, basic methods and basic experimental techniques which are closely related to the major as the key and difficult teaching content to explain in detail.

\section{B. Adopt Diversified Teaching Method and Teaching Means to Arouse Students' Learning Enthusiasm}

The content of theoretical knowledge of food chemistry course is relatively abstract, and the structure of the instrument used in operation is complex. Therefore, we must make full use of diversified teaching method and teaching means to improve students' interest in learning and enable students to learn knowledge efficiently within a limited time.

Heuristic teaching is an important teaching method in course content teaching. The artful establishment of situational problems and use of question and answer method and discussion method can motivate students to think positively and enable students to quickly understand and master relevant knowledge. It takes production practice as a living example to promote students to think, which can strengthen students' understanding on the methods and principles in theoretical knowledge. We can take those graduates in this major who have engaged in the related jobs of food chemistry in recent years for example, including Yili Group, Mengniu Group, Shenzhen Entry-exit Inspection and Quarantine Bureau, Local Animal Husbandry Bureau, Agricultural Bureau, Animal Inspection Station, Chia Tai Group, COFCO Corporation, Wens Group, Twins Group, Beijing Da Bei Nong Technology Group Co., Ltd, Shenzhen Kingsino Feed Co., Ltd and Changchun Haiyue Group, which can encourage students to have greater learning interest in the principle and operation of testing parts related to food chemistry and to put more emphasis on the mastery and understanding of knowledge. In the course of classroom teaching, language should be lively and vivid. We can give a brief introduction to the scientists and stories involved in the development of food chemistry, so as to arouse students' interest in listening to lectures.

In teaching method, we can make use of the advantages of multimedia teaching's strong visibility, rich knowledge, integration of text animation and audio-visual, so that students can better understand and memorize the difficult content gradually from easy to difficult stage and from abstract to specific concept. Certainly, multimedia teaching is not the only way of teaching. Therefore, based on the actual situation of students and teaching methods, this paper uses a combination of multimedia and blackboard teaching, visual aids and other methods to teach.

\section{Enhance Students' Practical Ability and Cultivate Students' Spirit of Innovation and Consciousness of Innovation}

A very important link in the practice part of food chemistry is to apply their knowledge ${ }^{[4,5]}$. In order to enhance the student's practical ability, this paper has adjusted the teaching plan of the food chemistry course and added experimental subjects closely related to the subject. Since the comprehensive and design experiments are related to the students' future work, we can arouse students' enthusiasm in learning and experimental operation. In the experiment, students are required to observe and record carefully, and to make a discussion and summary combining with the problems that arise in the experiment.

\section{RESEARCH CONTENT}

\section{A. Teaching Staff Construction}

We have established a reasonable and sustainable teaching staff through the implementation of plan of teacher's teaching ability promotion, plan of youth teacher education promotion and practice ability promotion, and enterprise and industry expert employment plan. Enterprise personnel with practical experience can be employed as part-time teachers to establish a "double-teacher and double-talented" teacher team with both teaching ability and practical ability. We play the role of the teacher development centre, and invest and establish a 5-year round of mechanism for the training of teachers' teaching ability, professional ability and vocational ability every year. Every year, we select teachers to enhance their abilities in high level applied universities, scientific research institutions and industrial enterprises at home and abroad. We encourage working teachers to study for doctoral degrees and conduct domestic and overseas academic visit. Through the reform of systems including teaching evaluation, performance appraisal, evaluation of professional titles, salary incentives, and university-enterprise exchange, we guide teaches to promote their initiative and enthusiasm, encourage and support teachers to conduct applied research and technology promotion for actual production and to timely keep abreast of the recent news in industry and technology development. 


\section{B. Construction of Syllabus and Teaching Content}

In the light of the characteristics of the development and progress of the discipline and students' understanding on this subject, we have revised and improved the syllabus, eliminated old teaching content, and added new teaching content so that the teaching content can keep pace with the times. In teaching, we should put emphasis on the content closely related to vocational education to explain it based on the training objectives of applied technical universities, and can selectively give a brief lecture to the content that is not particularly relevant and has been studied in previous basic disciplines in accordance with the actual situation. Because of the continuous progress of network resource technology, we need to update the knowledge constantly, pay close attention to the dynamic of the current curriculum, and make use of the network resource platform to arouse the students' interest in learning and stimulate the students' innovative ability.

\section{Construction of Teaching Method and Means}

We can take advantages of strong visibility and interactivity of network platform teaching to let the students have a perceptual knowledge on the studied analysis method, motivate students' thinking from easy to difficult stage and from abstract to specific concept and help them to memorize the content. We have now built an open online course for food chemistry on the Nongyuan online platform to facilitate students' learning and teaching interactive mode.

\section{Construction of Practical Teaching}

On the one hand, we have intensified the reform of content and method of experimental teaching and practice teaching, improved the content of experimental teaching, and added interest and design experiment content. We have improved the open system of the laboratory, and taught students in accordance of their aptitude, so that students can design and operate experiments independently. The teaching content is related to the students' work in the future, so the enthusiasm of students for learning and experimentation can be aroused. In the experiment, students are required to observe and record carefully, and to make a discussion and summary combining with the problems that arise in the experiment.

On the other hand, cultivate the approaches and measures of student's innovation ability, entrepreneurial ability and creative ability and promote teaching through scientific research and society service. To add new content and bring emotional appeal to classroom teaching, in addition to mastering the new information of subject, we should actively develop scientific research and society service and integrate its effect in the classroom teaching. In the process of serving the society, we have enhanced the college's ability to serve the society, improved its society radiation capabilities, and provided a large number of experimental internship opportunities, which greatly improves the students' operational ability and experimental skills. In addition, in order to improve students' scientific quality, our school also adopts innovative quality credit system to conduct assessment and examination. For example, students are encouraged to participate in student technology innovation projects, and under the guidance of relevant teachers, students' operational abilities and innovation abilities are cultivated. In the process of participating in scientific research projects, students are trained to be strict and conscientious in science, and master the skills for precise experimentation, so that they can obtain at least $4-8$ credits in related courses.

\section{E. Construction of Teaching Material}

We establish a high-quality and unique supporting system (including course materials, course tutoring materials, course experiment instructions and other teaching reference books) with complete content and system and in line with the requirements of the syllabus, to meet the teaching needs. With the support of the World Bank loan project funds, the schoolbased teaching textbooks are built, combining with the latest development knowledge at home and abroad, they will be updated irregularly on the Internet platform.

\section{F. Construction of Evaluation System}

We have carried out the reform and further refinement, and established a diversified assessment system. In both teaching and learning, we have attached great importance to the organic combination of process and results, and received good results. Through the reform of students' performance assessment methods, students pay attention to accumulating learning knowledge, and their attendance rate is significantly improved. At the same time, class atmosphere is active, and students take part in activities actively and pay more attention to the quality of the usual notes and homework, and they also operate actively in the experimental training class. Due to the increased means of urging students to learn, the burden on students to review for the test has been reduced, and they have a certain way to learn a difficult course.

We cultivate students' innovative spirit and innovative consciousness through the joint efforts of teachers and students in scientific research, undergraduate science and technology innovation activity and student graduation thesis experiments. By studying the food chemistry courses, students can not only master advanced food chemistry principles and methods, but also can exercise the practical ability. In the process of participating in scientific research projects and experiments, the students are trained to be strict and conscientious in science, and master the skills for precise experimentation, to lay a good foundation for future work or further scientific research.

\section{G. Construction of Network Sharing Platform}

The status of modern information technology, represented by mobile internet, big data, cloud computing, and the Internet of Things, is increasingly important in the economy and society. The application of modern information technology is of great significance to the construction of intelligent detection. We create a new inspection and supervision model, optimize resource allocation, and reduce cost detection. We strengthen the research, cross-platform and cross-regional inspection services for mobile application technology of mobile Internet. We establish a combination of inspection and inspection processes to complement each other and realize on-line inspection. Strengthen the analysis of test data, establish a rapid response mechanism, focus on customers, and achieve precise push service and customized inspection. The support of 
ecosystem, establishment of this system and multi-agent platform and innovative technology of Internet plus platform and users will construct a mutual benefit and win-win result and finally achieve the sustainable development of modern inspection services model.

\section{CONCLUSION}

In a word, science is developing and knowledge is being updated. The teachers who teach food chemistry sustain great responsibilities of disseminating knowledge and cultivating quality talents. In order to adapt to the current requirements, the construction and practice of the Internet plus Food Chemistry curriculum under the background of transition is of great significance.

\section{REFERENCES}

[1] Zhang Wenbin, Yang Ruijin, Lu Rongrong, et al. Comparison of Food Chemistry Course between China and United States[J]. Journal of Anhui A gricultural Sciences, 2011,39(8):4982-4984. 张文斌,杨瑞金,卢 蓉蓉, 等. 中美高校《食品化学》课程比较 [J]. 安徽农业科 学,2011,39(8): 4982-4984.

[2] Chen Fuyu. Food Chemistry[M]. China Zhijian Publishing House, 2017. 陈福玉.食品化学 [M].中国质检出版社, 2017.

[3] Fu Xiaoping, Li Lingfei, Zhao Lingzhi. The Teaching Reform and Practice in Course of Food Chemistry[J]. Modern Agricultural Sciences and Technology, 2013,11:343-344. 付晓萍,李凌飞,赵灵芝.食品化学 课程教学改革与实践 [J].现代农业科技,2013,11:343-344.

[4] Sun Yuanlin, Li Nan, Wang Yanping. Reform of Food Chemistry Experiment Teaching, Cultivation of Students' Innovative Ability[J]. Farm Products Processing, 2016(6): 81-84. 孙元琳,李楠,王艳萍.改革 食品化学实验教学,培养学生创新能力[J].农产品加工,2016(6): 81-84.

[5] Zhang Cuan, Jia Xiaoli, Cai Huazhen, et al. Discussion on Diversified Teaching of Food Chemistry Course in Application-oriented Universities[J]. Journal of Suzhou University, 2012,27(8): 116-118. 张 亦,贾小丽,蔡华珍,等.应用型本科高校食品化学课程多元化教学探讨 [J].宿州学院学报,2012,27(8): 116-118.

[6] An Yanxia, Zhang Jian, Li Mengqin. Exploration on Talent Training Model of Internet+ for University Student in Food Science Major [J]. Journal of Suzhou University, 2017,45(4):165-167. 安艳霞,张剑,李梦 琴. 食品专业结合 “互联网 + ” 人才培养模式的探索 [J].广州化 工,2017,45(4):165-167. 